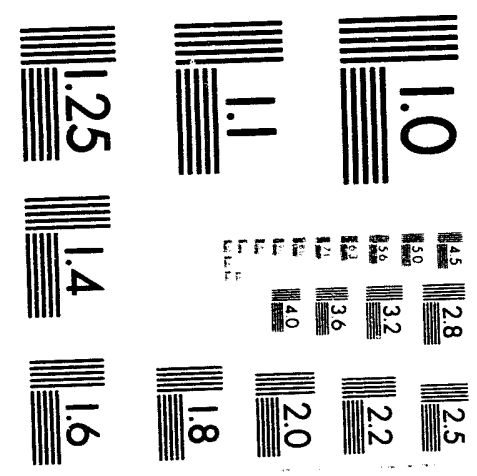



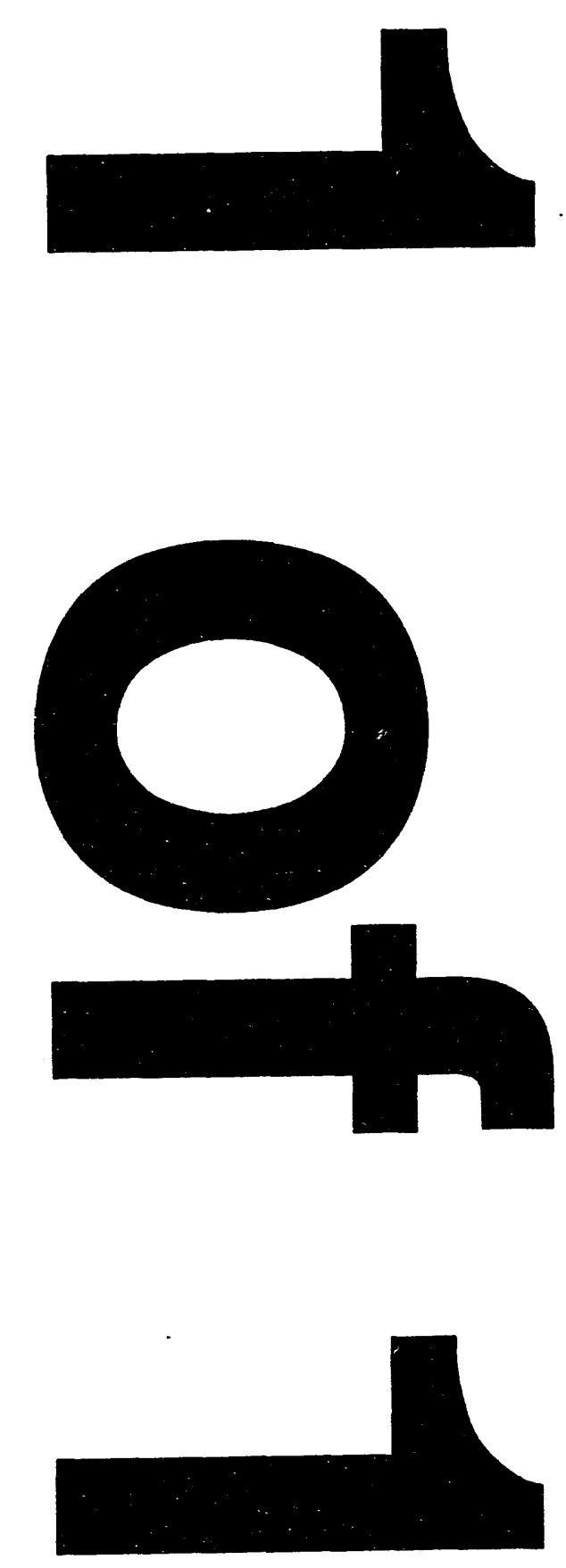
JACS Communication

$$
\begin{gathered}
\text { ANL/CAM/PP.- } 73178 \\
0 .-11904 \\
\text { OSTI }
\end{gathered}
$$

\title{
Aromatic Carbonium Ions in Liquid Alkanes and Alcohols From Laser Photoionization and Pulse Radiolysis*
}

\author{
A. D. Trifunac, A.-D. Liu, M. C. Sauer, Jr. and C. D. Jonah \\ Chemistry Division, Argonne National Laboratory, Argonne, IL 60439
}

\begin{abstract}
Aromatic carbonium ions are observed in photoionization and radiolysis of aromatic compounds in hydrocarbons and alcohols. These aromatic carbonium ions result from the protonation of aromatic molecules by the protonated species of hydrocarbons and alcohols which are ubiquitous in the "high energy" chemistry processes. The condensed-phase optical absorption spectra of aromatic radical cations and aromatic carbonium ions are essentially identical. The assignment of the carbonium ion species is feasible by considering the lifetimes, kinetics, scavenger and solvent effects on radical cation and carbonium ion lifetimes.
\end{abstract}

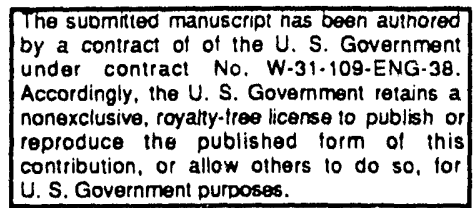

${ }^{*}$ Work performed under the auspices of the Office of Basic Energy Sciences, Division of Chemical Science, US-DOE under contract number W-31-109-ENG-38. 
Aromatic carbonium ions $\left(\mathrm{AH}_{2}^{+}\right)$resulting from the protonation of aromatic molecules $(\mathrm{AH})$ have recently been observed in laser flash photolysis studies in 1,1,1,3,3,3-hexafluoro-2 propanol (HFIP). ${ }^{1}$ By using this solvent, several protonated aromatic cations were observed in our recent laser flash photolysis experiments of several aromatic compounds, such as anthracene, acenaphthene, naphthalene, pyrene and perylene. As an example, figure 1 shows the result of anthracene in HFIP. A long-lived species with an absorption maximum around $715 \mathrm{~nm}$ is observed. On the basis of the known properties of HFIP, ${ }^{1}$ we can assign this long-lived species to a carbonium ion of anthracene.

\section{FIGURE 1 HERE}

Figure 1. Transient absorption spectrum observed in $308 \mathrm{~nm}$ laser flash photolysis of $5 \times 10^{-4}$ $\mathrm{M}$ anthracene in HFIP. The insert shows the time profile at $715 \mathrm{~nm}$ at early time $(<1 \mu \mathrm{s}$, upper trace) and at later time $(1-400 \mu \mathrm{s}$, lower trace). The spectra and time profiles are similar in air, argon or $\mathrm{SF}_{6}$ saturated solutions.

Moreover, we find that such aromatic carbonium ions are ubiquitous in laser photoionization and in pulse radiolysis in hydrocarbons and alcohols. Surprisingly, no previous observations of such substituted cyclohexadienyl cations have been reported in pulse radiolysis or in laser photoionization. Such species were observed by NMR and optical spectroscopy in super acids some years ago. ${ }^{2}$ Here we present examples of the observation of aromatic carbonium ions in polar and nonpolar solvents and discuss the mechanism of their production.

In the radiation chemistry of alcohols, the accepted mechanism ${ }^{3}$ of production of charge pairs and the conversion of the initially produced solvent radical cation by proton transfer is given by reactions (1) and (2) . 


$$
\mathrm{ROH}^{+} \cdot+\mathrm{ROH} \rightarrow \mathrm{RO} \cdot+\mathrm{ROH}_{2}^{+}
$$

Reaction (2) is very rapid and usually occurs before the $\mathrm{ROH}^{+} \cdot$ undergoes any other reactions.

We have recently suggested that ion-molecule reactions in hydrocarbon radiolysis are also common: 4

$$
\begin{aligned}
& \mathrm{RH} \text { - } \mathrm{RH}^{+} \cdot+\mathrm{e}^{-} \\
& \mathrm{RH}^{+} \cdot+\mathrm{RH} \rightarrow \mathrm{R} \bullet+\mathrm{RH}_{2}^{+}
\end{aligned}
$$

While the existence of radicals, electrons and radical cations can be easily established by time-domain optical spectroscopy, ${ }^{5}$ conductivity ${ }^{6}$ or magnetic resonance, ${ }^{4 a}$ the proton adduct $\mathrm{RH}_{2}^{+}$ is not expected to possess a readily accessible signature.

In our recent study of the two-photon ionization photoionization of aromatic molecules (AH) in hydrocarbon $(\mathrm{RH})$ and alcohol $(\mathrm{ROH})$ solutions, we have suggested that a proton transfer occurs, giving rise to $\mathrm{RH}_{2}^{+}$or $\mathrm{ROH}_{2}^{+}$via ion-molecule reactions of the (presumably excited) radical cation of the solute: 7

$$
\begin{gathered}
\mathrm{AH} \stackrel{\text { hv }}{\rightarrow} \mathrm{AH}^{*} \stackrel{\text { hv }}{\rightarrow} \mathrm{AH}^{+} \cdot *+\mathrm{e}^{-} \\
\mathrm{AH}^{+} \cdot+\mathrm{ROH} \rightarrow \mathrm{A} \cdot+\mathrm{ROH}_{2}^{+} \\
\mathrm{AH}^{+} \cdot *+\mathrm{RH} \rightarrow \mathrm{A} \cdot+\mathrm{RH}_{2}^{+} \\
\mathrm{AH}^{+} \cdot * \rightarrow \mathrm{AH}^{+} \cdot
\end{gathered}
$$


The presence of the carbonium ions $\mathrm{RH}_{2}^{+}$or $\mathrm{ROH}_{2}^{+}$in radiolysis or photoionization experiments can be established by their reaction with the aromatic compounds ( $\mathrm{AH})$, which exhibit considerably greater proton affinity than hydrocarbons or alcohols. 8

Thus, in laser flash photoionization and in radiolysis we should be able to observe reactions (9) and (10) .

$$
\begin{gathered}
\mathrm{ROH}_{2}^{+}+\mathrm{AH} \rightarrow \mathrm{ROH}+\mathrm{AH}_{2}^{+} \\
\mathrm{RH}_{2}^{+}+\mathrm{AH} \rightarrow \mathrm{RH}+\mathrm{AH}_{2}^{+}
\end{gathered}
$$

The formation rate of $\mathrm{AH}_{2}^{+}$should depend on the $\mathrm{AH}$ concentration and also on the lifetime of $\mathrm{ROH}_{2}^{+}$or $\mathrm{RH}_{2}^{+}$. Also, in dilute solution, $\mathrm{AH}_{2}^{+}$should appear on a longer time scale than the initial excitation or ionization periods. Indeed, by laser flash photolysis and pulse radiolysis we observe transient species with these kinetic characteristics in hydrocarbons and alcohols containing aromatic molecules. The transient absorption spectra obtained in solution of anthracene in isopropanol and in iso-octane are shown in figure 2 and figure 3 as examples.

\section{FIGURE 2 HERE}

Figure 2. Spectra and kinetics of formation of transient species in 2-propanol containing $5 \times 10^{-4}$ $\mathrm{M}$ anthracene and saturated with $\mathrm{SF}_{6}$ produced by $308 \mathrm{~nm}$ laser flash photolysis and pulse radiolysis. The data from pulse radiolysis were multiplied by 2.2 to match the maximum value of photolysis data at $720 \mathrm{~nm}$. The width of laser pulse is $20 \mathrm{~ns}$ and width of electron pulse is $4 \mathrm{~ns}$. 


\section{FIGURE 3 HERE}

Figure 3. Spectra and kinetics of formation of transient species in iso-octane containing anthracene (radiolysis $2 \times 10^{-4}$; photolysis $5 \times 10^{-4} \mathrm{M}$ ) and saturated with $\mathrm{SF}_{6}$, produced by 308 $\mathrm{nm}$ laser flash photolysis and pulse radiolysis. In plotting the spectra, the data from pulse radiolysis were multiplied by 4.3 to match the maximum value of photolysis data at $730 \mathrm{~nm}$.

Consider the transient species at $30-40$ ns in photolysis. From previous reports 9,10 , the anthracene radical cation is produced by the biphotonic process through reactions ( 5 and 8$)$. This radical cation is also observed in HFIP (see $30 \mathrm{~ns}$ spectrum in figure 1) which implies a similar biphotonic process in HFIP.

Second, consider the slow formation of a long-lived species in 2-propanol (photolysis and radiolysis) and in iso-octane (radiolysis). It has an absorption maximum at $720 \mathrm{~nm}$ in 2 -propanol and $730 \mathrm{~nm}$ in iso-octane. It is produced at a rate proportional to the concentration of anthracene. Comparing the similarities with respect to absorption maxima and kinetic characteristics of this species with the species we observed in HFIP, we assign it as anthracene carbonium ion $\mathrm{AH}_{2}^{+}$. The bimolecular reaction rate constant of $\mathrm{AH}_{2}^{+}$formation in reaction (9) is measured as $8 \times 10^{9} \mathrm{M}^{-1} \mathrm{~s}^{-1}$ by photolysis and $6 \times 10^{9} \mathrm{M}^{-1} \mathrm{~s}^{-1}$ by radiolysis. More evidence comes from the acceleration of the formation of this species by adding KOH or amines. This implies the scavenging of $\mathrm{ROH}_{2}^{+}$by $\mathrm{OH}^{-}$ or amines. The bimolecular reaction rate constant of $\mathrm{k}\left(\mathrm{ROH}_{2}^{+}+\mathrm{OH}^{-}\right)$was measured as $4 \times 10^{9}$ $\mathrm{M}^{-1} \mathrm{~s}^{-1}$. In photoionization experiments the formation of long lived carbonium ions in hydrocarbons is more difficult to see since the free ion yield of $\mathrm{RH}_{2}^{+}$in hydrocarbons is considerably less than free ion yield of $\mathrm{ROH}_{2}^{+}$in alcohols. However the slow formation of $\mathrm{AH}_{2}^{+}$is clearly observable in pulse radiolysis in iso-octane (insert in figure 3).

An unexpected situation exists with respect to the optical absorption spectra of the radical cations $\left(\mathrm{AH}^{+} \cdot\right)$ and the carbonium ions $\left(\mathrm{AH}_{2}^{+}\right)$. In most instances, our results indicate that the spectra are essentially identical. Therefore, kinetic observations and arguments are critical in 
inferring which species is present at a given time in a particular solvent. The situation is most clear-cut in the pulse radiolysis of dilute solutions of the aromatic molecules (AH) in alcohols, where $\mathrm{AH}^{+}$. is not formed to a significant extent as a primary radiolytic product, and its formation from $\mathrm{ROH}^{+}$. is not possible because proton transfer from $\mathrm{ROH}^{+}$- to $\mathrm{ROH}$, reaction (2), is extremely fast. Consistent with our previous finding that alkane radical cations are short lived ${ }^{4,11}$, we conclude that a slow growth (inset Figure 3) observed in pulse radiolysis in hydrocarbons can be assigned to the aromatic carbonium ion.

The observation of aromatic carbonium ions provides a critical confirmation of the role of ion-molecule reactions in photoionization and photolysis. These findings, while still preliminary, may resolve many conflicting observations in radiolysis and in photoionize+ion. More work is needed to quantitatitvely test the mechanism of formation and kinetic characteristics of these apparently ubiquitous carbonium ions. 


\section{References}

1. Steenken, S.; McClelland, R. A. J. Am. Chem. Soc. 1990, 112, 9648.

2. a) Olah, G. A.; Steral, J. S.; Asencio, G.; Liang, G.; Forsyth, D. A.; Mateescu, G. D. J. Am. Chem. Soc. 1978, 100, 6299.

b) Olah, G.A.; Pittman, Jr., C.U.; and Symons, M.C.R.. in "Carbonium ions". Interscience publication, John Wiley \& sons, New York. 1968. Volume 1. Chapter 5.

c) Gallina, G.; Mackor, E.L.; and Stuart, A.A.V.; Mol. Phys, 1958, 1, 123.

3. a) Freeman, G.R. in "Actions Chimiques et Biologiques des Radiations", Masson et Cie, Paris, 1970. Part II, 87-104.

b) Freeman, G.R. in "The Study of Fast Processes and Transient Species by Electron Pulse Radiolysis", eds. Baxandale, J.H. and Busi, F.; D Reidel Publishing Company, Dordrecht, Holland, 1982. $399-416$.

4. a) Werst, D. W.; Bakker, M. G.; Trifunac, A. D. J. Am. Chem.Soc. 1990, 112, 40.

b) Sauer, Jr., M. C.; Werst, D. W.; Jonah, C. D.; Trifunac, A. D. Radiat. Phys. Chem. $1991,37,461$.

5. Le Motais, B. C.; Jonah, C. D. Radiat. Phys. Chem. 1989, 33, 505.

6. a) Sauer, Jr., M. C.; Trifunac, A. D.; McDonald, D. B.; Cooper, R. J. Phys. Chem. 1984, $88,4096$.

b) Sauer, Jr., M. C.; Schmidt, K. H.; Liu, A. -D. J. Phys. Chem. 1987, 91, 4836.

7. Trifunac, A. D.; Liu, A.-D., Loffredo, D. Proc. 29th Yamada Conference on Dynamics and Mechanism of Electron Transfer and Related Phenomena, Mataga, N.; Ed., Elsevier, in press.

8. a) Meot-Ner, M.; J.Phys.Chem, 1980, 84, 2716.

b) Walder, R.; Franklin,J.L.; Int. J. Mass Spect. and Ion Phys., 1980, 36, 85.

9. Delaire, J.A.; Castella, M.; Faure, J.; Vanderauwera, P.; and De Schryver, F.C.; Nouv. J. Chim., 1984, 231.

10. Baker, M.G.; Trifunac, A.D.; J. Phys. Chem. 1991, 95, 550.

11. Sauer, M.C. Jr.; Jonah, C.D.; Naleway, C.A.; J. Phys. Chem. 1991, 95, 730. 


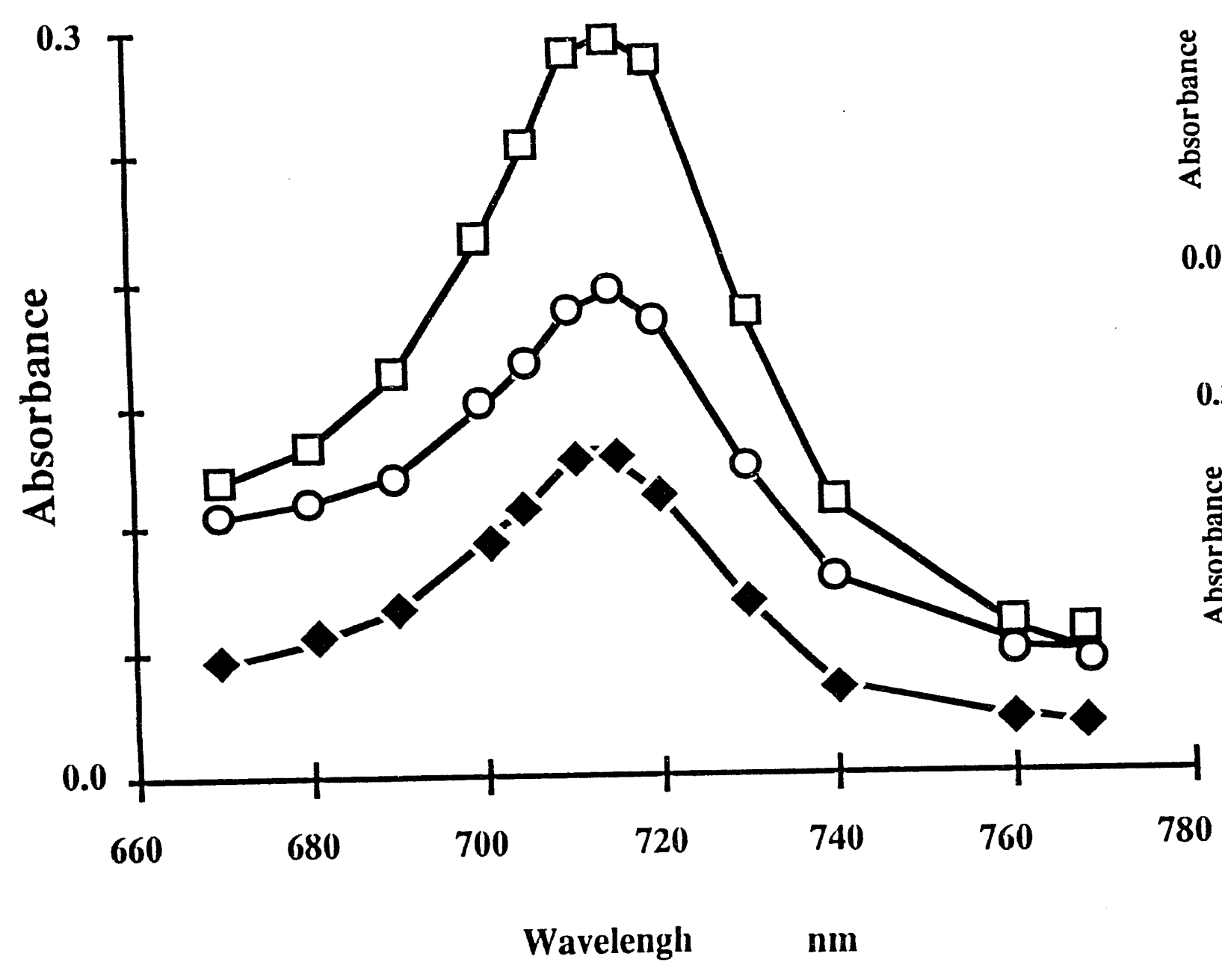

5E-4 M Anthracene in HFIP. ( (CF3)2CHOH) $.308 \mathrm{~mm}$ laser photolysis
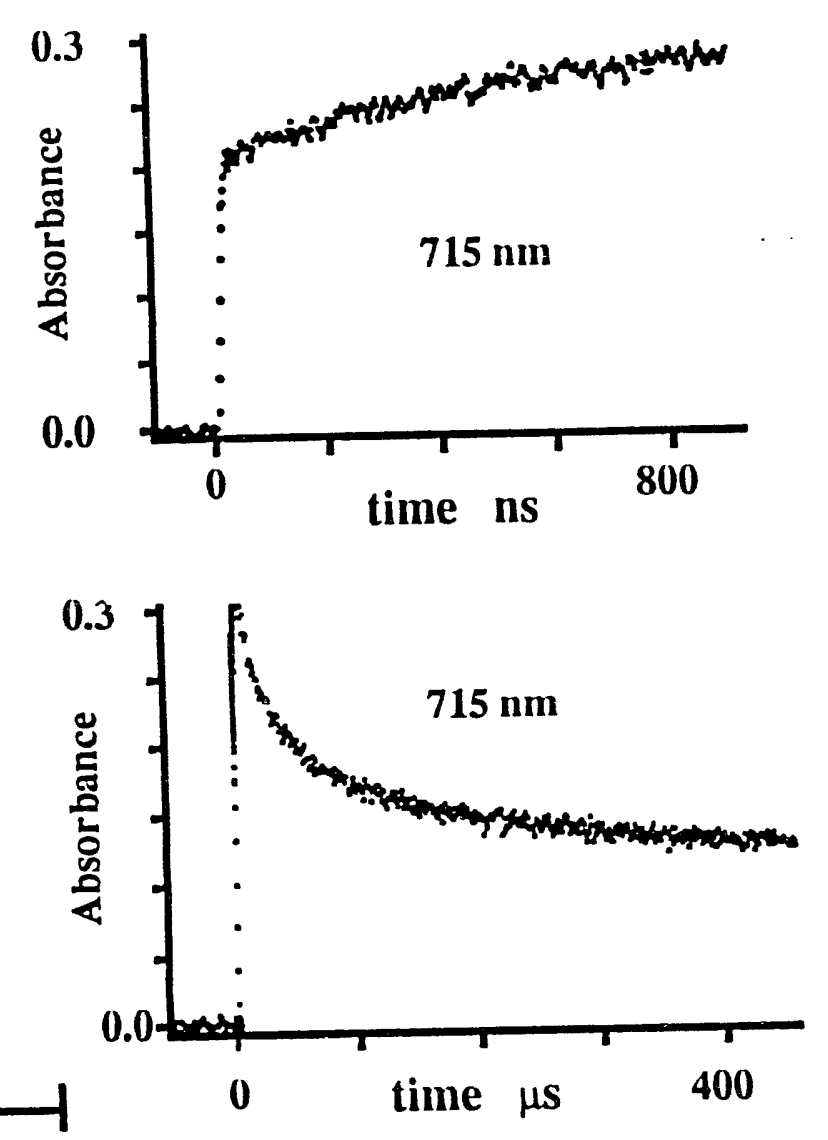

O $30 \mathrm{~ns}$

$\square \quad 5 \mu s$

$>400 \mu \mathrm{s}$ 


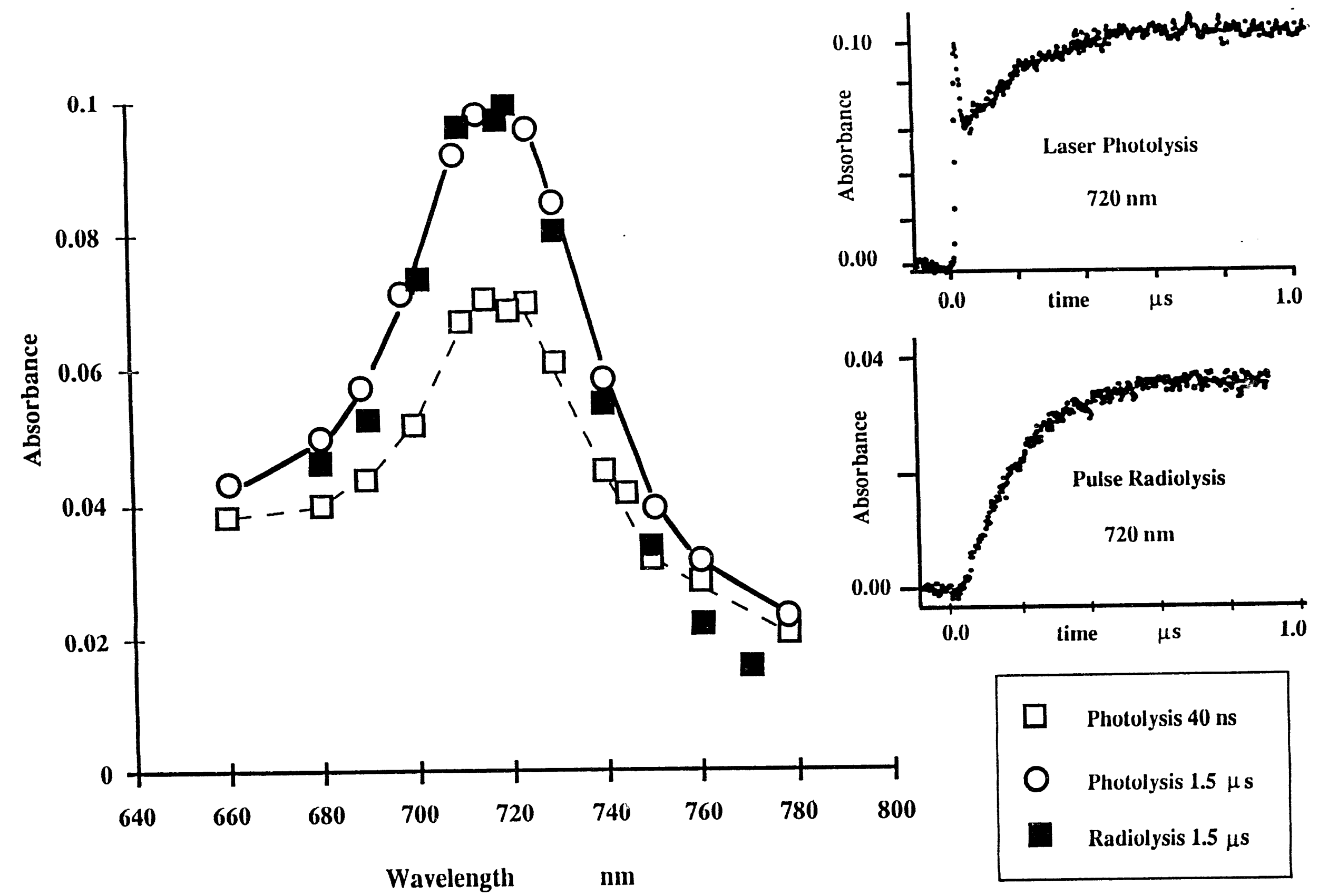




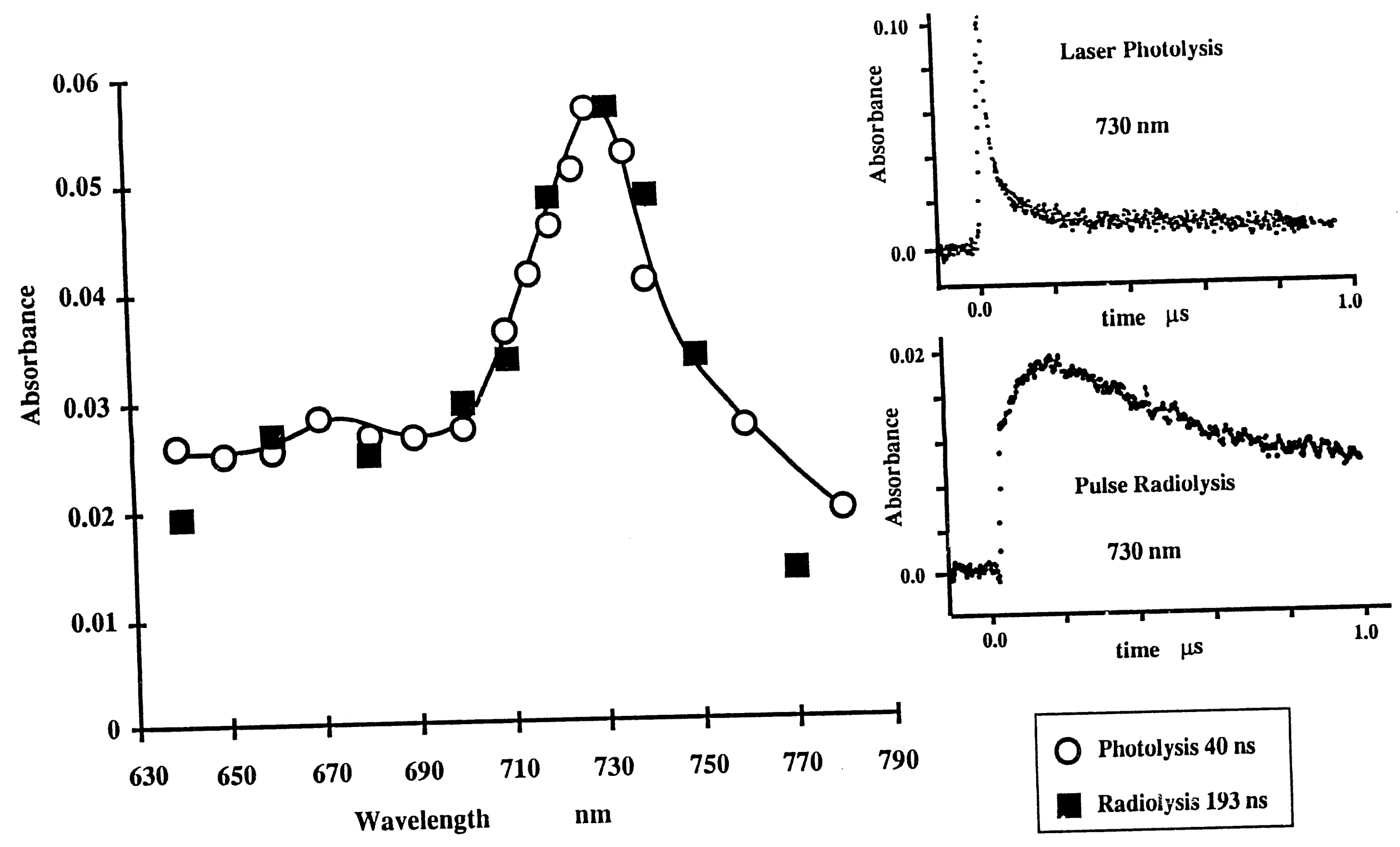

Anthracene in iso-octane, + SF6, by laser flash photolysis (5E-4 M) and pulse radiolysis (2E-4 M).

Figure 3. 

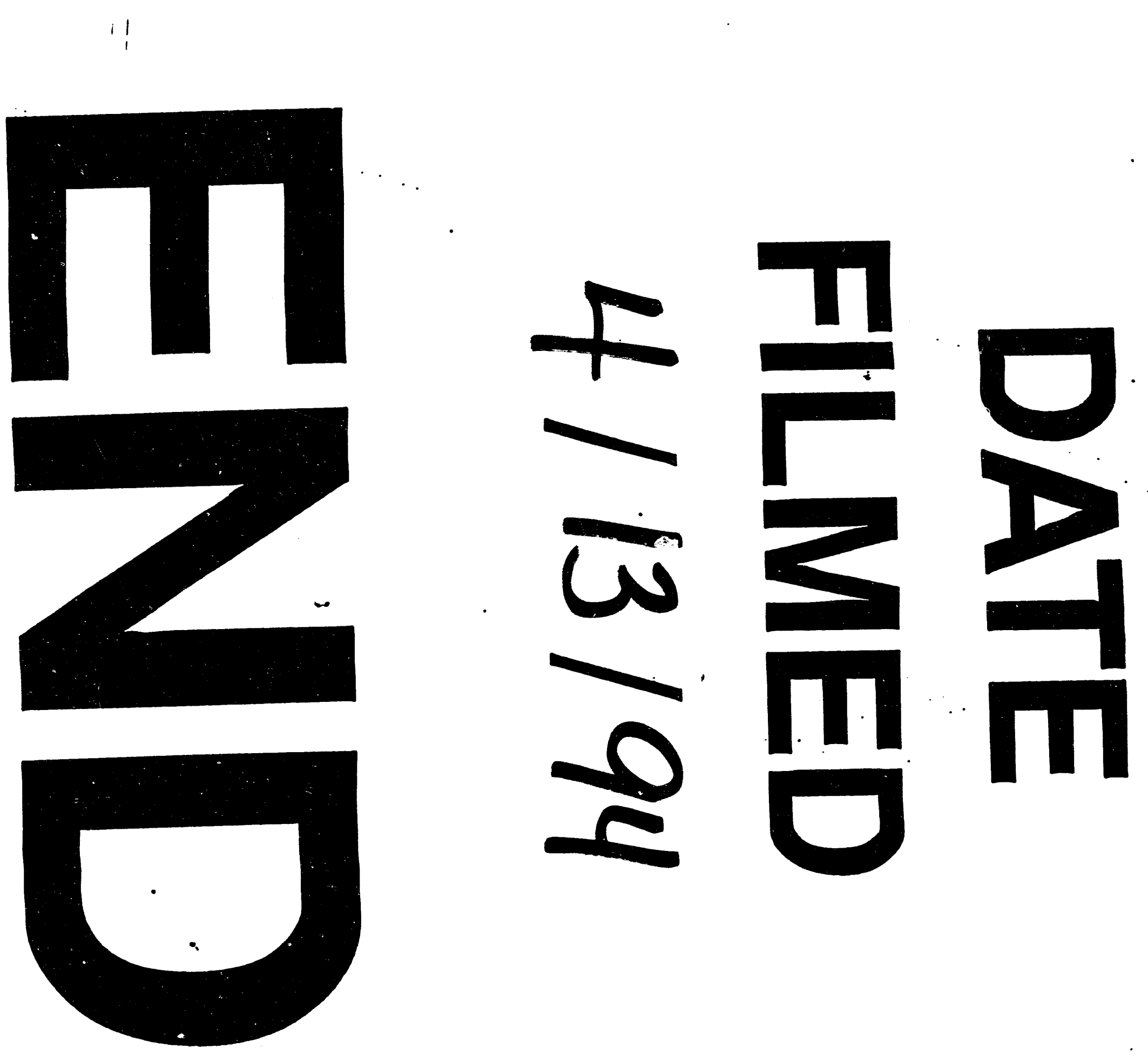